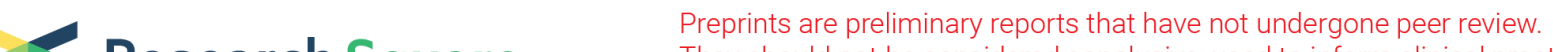 Research Square
They should not be considered conclusive, used to inform clinical practice,
or refernced by the media as validated information.
}

\section{S-Ketamine Exerts Antidepressant Effects by Regulating Rac1 Gtpase Mediated Synaptic Plasticity in the Hippocampus of Stressed Rats}

\section{Xianlin Zhu}

Central Hospital of Enshi Tujia and Miao Autonomous Prefecture https://orcid.org/0000-0002-9764451X

\section{Fan Zhang}

People's Hospital of Bishan Distict

\section{Yufeng You}

Central Hospital of Enshi Tujia and Miao Autonomous Prefecture

\section{Hongbai Wang}

Chinese Academy of Medical Sciences \& Peking Union Medical College Fuwai Hospital

\section{Su Yuan}

Chinese Academy of Medical Sciences \& Peking Union Medical College Fuwai Hospital

\section{Banglin Wu}

Central Hospital of Enshi Tujia and Miao Autonomous Prefecture

\section{Rongyu Zhu}

Central Hospital of Enshi Tujia and Miao Autonomous Prefecture

Dawei Liu

Yongchuan Hospital of Chongqing Medical University

\section{Fuxia Yan}

Chinese Academy of Medical Sciences \& Peking Union Medical College Fuwai Hospital

\section{Zaiping Wang ( $\sim 2016921 @$ hbmzu.edu.cn )}

Central Hospital of Enshi Tujia and Miao Autonomous Prefecture https://orcid.org/0000-0001-55867523

\section{Research Article}

Keywords: Depression, Ketamine, Rac1 GTPase, synaptic plasticity, Long-term potentiation

Posted Date: September 13th, 2021

DOI: https://doi.org/10.21203/rs.3.rs-790608/v1 
License: (c) (i) This work is licensed under a Creative Commons Attribution 4.0 International License. Read Full License 


\section{Abstract}

Clinical studies have found that ketamine has a rapid and lasting antidepressant effect, especially in the case of patients with major depressive disorder (MDD). The molecular mechanisms, however, remain unclear. In this study, we observe the effects of S-Ketamine on the expression of Rac1, neuronal morphology, and synaptic transmission function in the hippocampus of stressed rats. Chronic unpredictable mild stress (CUMS) was used to construct stressed rats. The rats were given a different

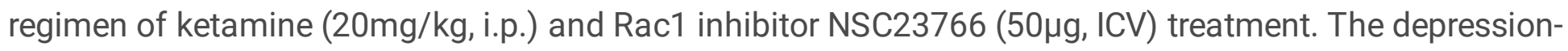
like behavior of rats was evaluated by sucrose preference test and open-field test. The protein expression of Rac1, Glur1, synapsin1, and PSD95 in the hippocampus was detected by Western blot. Pull-down analysis was used to examine the activity of Rac1. Golgi staining and electrophysiological study were used to observe the neuronal morphology and long-term potentiation (LTP). Our results showed that ketamine can up-regulate the expression and activity of Rac1; increase the spine density and the expression of synaptic-related proteins such as Glur1, Synapsin1, and PSD95 in the hippocampus of stressed rats; reduce the CUMS-induced LTP impairments; and consequently improve depression-like behavior. However, Rac1 inhibitor NSC23766 could have effectively reversed ketamine-mediated changes in the hippocampus of rats and counteracted its antidepressant effects. The specific mechanism of Sketamine's antidepressant effect may be related to the up-regulation of the expression and activity of Rac1 in the hippocampus of stressed rats, thus enhancing synaptic plasticity.

\section{Introduction}

Depression is a common psychiatric illness with high morbidity and disability rates, resulting in enormous public health costs and personal suffering (Gu et al. 2013). According to the World Health Organization, depression has become the second leading cause of illness, affecting approximately $17 \%$ of the world's population. More than one million people per year are estimated to have committed suicide due to depression (Chapman and Perry 2008; Kessler et al. 2003). Due to the lack of conventional and effective antidepressants, the relapse rate of patients with first-onset depression is as high as $50 \%$ within the first 5 years, and the lifetime prevalence reaches 15\% 20\% (Angst et al. 2013).

Traditional antidepressants, such as selective serotonin reuptake inhibitors (SSRIs) and stricyclic antidepressants, usually have slow onset for therapeutic response (takes several weeks) and a low remission rate (40\% 50\%) (Cipriani et al. 2016; Sinyor et al. 2010). In addition, more than $30 \%$ of depression patients exhibit obvious resistance responses to currently available antidepressant medications, especially for patients with major depressive disorder (MDD) (Cipriani et al. 2016; Duman and Aghajanian 2012). In recent years, clinical studies have found that the intravenous anesthetic ketamine has a rapid and lasting antidepressant effect, especially for patients with MDD and who are treatment-resistant or show poor response to SSRIs (Wang et al. 2012; Cornwell et al. 2012). A single dose of ketamine $(0.5 \mathrm{mg} / \mathrm{kg}$, sub-anesthetic doses) can induce antidepressant effects after 40 minutes, and more than one-third of patients show obvious improvement one week after administration (Lenze et 
al. 2016). However, the underlying molecular mechanism of ketamine's antidepressant effect remains poorly understood.

A growing number of studies have shown that the pathogenesis of depression is related to changes in synaptic plasticity, including changes in synaptic structure and transmission function (Duman and Aghajanian 2012; Kang et al. 2012). Brain imaging studies found that the volume of limbic areas such as the prefrontal cortex and hippocampus (involved in emotion, mood, and cognitive functions) were reduced, accompanied by massive neuronal atrophy and a decreased number of synapses (Rajkowska et al. 1999). The autopsy analysis further confirmed that the dorsolateral prefrontal cortex (dIPFC) and hippocampus neuronal atrophy, synaptic loss, and synaptic proteins were altered in patients with MDD (Drevets 2000).

Previous studies have shown that Rac1 (a member of the small G protein Rho family, Rho-GTPase), can cause neuronal cytoskeleton remodeling and regulation of synaptic plasticity (Li et al. 2000; Luo 2002). Activation or up-regulation of Rac1 expression can lead to dramatic changes in the morphology of dendritic spines, including an extension of dendrites and an increase in dendritic spine density (Um et al. 2014). The loss of Rac1 will directly affect the formation of nerve synapses and neural circuits (Pennucci et al. 2016). Recent studies have shown that abnormal expression of Rac1 is associated with a variety of diseases, including depression, autism, and fragile X syndrome (Li et al. 2015; Chen et al. 2010;Golden et al. 2013). Chronic social frustration stress promotes down-regulation of Rac1 expression in the nucleus accumbens of mice, loss of dendritic spines, and induces depression-like behaviors such as social avoidance and anhedonia (Golden et al. 2013). However, whether Rac1 plays an important role in the antidepressant effect of ketamine is unclear.

In this study, we use stressed rats with depression-like behavior to observe the effects of s-ketamine on Rac1 activity, protein expression, and synaptic plasticity of the hippocampus, and elucidate the possible mechanism of ketamine's antidepressant effect.

\section{Materials And Methods \\ 2.1. Animals}

Adult male Sprague-Dawley rats (2-3 months, 200-250 g) were obtained from the Experimental Animal Center of Hubei Institute of Selenium and Human Health. Rats were housed in standardized laboratory conditions $\left(23 \pm 2^{\circ}, 60 \%\right.$ humidity, $12 \mathrm{~h}$ light $/ 12 \mathrm{~h}$ dark, free access to water and food ) for a week to allow them to adapt to the new environment. All animal experimental protocols were approved by the Ethical Committee of Hubei Institute of Selenium and Human Health (No. HB2017-003) and the animal care guidelines of the National Institute of Health were followed. The sample size is calculated using the software PASS and One-Way Analysis of Variance F-Tests, as follows: $80 \%$ test power and $5 \%$ type I error. The behavioral data of rats (Hao et al. 2016) as the primary endpoint, an estimated 15\% standard deviation of the mean between groups $(\sigma \mathrm{m})$ and $30 \%$ within-group standard deviation $(\sigma)$ were detected. 
The output result was the effect size of $f=0.5$ and $N=12$. For molecular analysis (the second end point), we estimate that $15 \%$ standard deviation of the mean between groups and $20 \%$ within-group standard deviation was detected. The output result was the effect size of $f=0.75$ and $N=6$. The blindness was achieved through the following methods: (1) After the rats were numbered, a researcher randomly grouped them according to the number and prepared the corresponding treatment drugs (only the number was marked); (2) Other researchers only knew the number of rats but not the grouping, and performed subsequent behavioral experiments, biochemical analysis and statistical analysis.

\subsection{Model of stressed rats}

CUMS procedure was used to construct the model of stressed rats with depression-like behavior as previously documents (Banasr et al. 2007). Rats were kept in solitary cages and received modeling stress for 28 consecutive days, with different stressors each day. One of the nine stressors was randomly selected: horizontal shaking for 20 minutes; cage tilting (45*) for 24 hours; continuous lighting for 24 hours; clamp the tail for 1 minute; damp sawdust for 24 hours; food deprivation for 24 hours; water deprivation for 24 hours; swimming in cold water for 5 minutes $(4 \circ C)$; social crowding (20/cage);

\subsection{Experiment treatments}

\subsubsection{Experiment 1}

Forty-eight stressed rats were randomly assigned to four groups: group D, DK, DNK, and DN $(n=12)$. Twelve healthy rats (same age and batch) were included in the control group (group C), and did not receive drug treatment. Group D was treated with intracerebroventricular (ICV) and intraperitoneal (IP) injection saline $(10 \mathrm{ml})$; group DK was treated with saline $(10 \mu \mathrm{l}, \mathrm{ICV})$ and s-ketamine $(20 \mathrm{mg} / \mathrm{kg}, \mathrm{IP}$, preparation as $2 \mathrm{mg} / \mathrm{ml}, \mathrm{H} 20193336$, Hengrui Medicine, China); group DNK was treated with Rac1

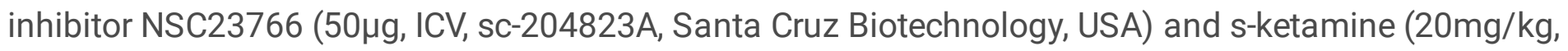

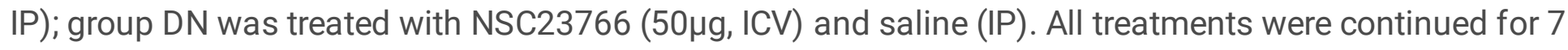
days, once a day.

\subsubsection{Experiment 2}

Six healthy rats were included in the control group (group C). Twenty-four stressed rats were randomly assigned to four groups $(n=6)$ : group D, DK, DNK and DN. This part was used for the electrophysiological study. The treatment schemes for rats in each group were the same as those in experiment 1 except that these rats did not undergo behavioral tests.

\subsection{Intracerebroventricular administration}

$50 \mu \mathrm{g}$ Rac1 specific inhibitor (NSC23766) was dissolved in $10 \mu \mathrm{L}$ saline. 15 minutes before the injection of s-ketamine, the prepared NSC23766 was injected into the left cerebral ventricle of rats. Saline was injected into the cerebral ventricle of the vehicle control rats. For intracerebroventricular administration, the rats were anesthetized using sodium pentobarbital $(50 \mathrm{mg} / \mathrm{kg}, \mathrm{IP})$, then placed on a stereotaxic instrument (Narishige, Tokyo, Japan), and the position of the ear rods was adjusted. implanted the 
cannula into the left cerebral ventricle (bregm as the center, lateral $1.5 \mathrm{~mm}$; anteroposterior $\pm 0.8 \mathrm{~mm}$ and depth $3.5 \mathrm{~mm}$ ) (Zhang et al. 2009). Drug injection was administered using a micro-syringe at a rate of 2 $\mu \mathrm{L} / \mathrm{min}$ by the cannula.

\subsection{Behavioral tests \\ 2.5.1 Sucrose preference test}

Sucrose preference test was used to evaluate anhedonia (core symptom of depression) in rodents (Luo et al. 2010). The Sucrose preference test was administered after the CUMS procedures and s-ketamine treatment. In order to acculturate the rats to the sucrose solution, two bottles of $1 \%$ sucrose solution were provided during the first 24 hours. After 23 hours of fasting and water deprivation, the rats were allowed to drink freely for one hour. At this time, the rat was provided with two identical bottles, one containing $1 \%$ sucrose and and the other bottle was sterile water. Sucrose preference percentage (SPP) $=($ sucrose solution consumption /sterile water consumption + sucrose solution consumption) $\times 100$

\subsubsection{Open-field test}

The Open Field Test was performed to evaluate the exploratory behavior of rats in an unfamiliar environment (Hallam et al. 2004). A black wooden square platform $(100 \times 100 \times 50 \mathrm{~cm})$, placed in a quiet, dim room. The white marking line divides the floor of the apparatus into 25 square grids of equal size. Animals were placed in the center of the platform, allowed to move freely for five minutes, and count the number of crossed squares (indicating spontaneous locomotor) and the frequency of rearing (rats stand completely on their hind legs, indicating exploratory activities). The test was administered after the CUMS procedure and s-ketamine treatment.

\subsection{Tissue biochemical analysis}

\subsubsection{Tissue preparation}

After the last behavioral test was completed, 6 rats from each group were decapitated under $2 \%$ sodium pentobarbital ( $50 \mathrm{mg} / \mathrm{kg}, \mathrm{IP}$ ) anesthesia, and bilateral hippocampus were taken out on ice and immediately cooled in liquid nitrogen tanks, then stored in -80 ॰C refrigerators. This part of the hippocampus was used for real-time PCR, western blotting and Rac1-GTP binding assay. An additional six rats were used for the Golgi staining.

\subsubsection{Real-time PCR analysis}

Following the manufacturer's instructions, Trizol reagent (Invitrogen Technology, Carlsbad, CA, USA) was used to extract total RNA from hippocampal tissue. Reverse transcription was performed using Goldenstar $^{\text {TM }}$ RT6 cDNA Synthesis Kit (Qingke Bio Inc., China). ABI PRISM 7900 sequence detection system with SYBR Green qPCR Master Mix (Applied Biosystems, CA, USA) was used for real-time PCR analysis. The reaction conditions for the holding stage were $95 \circ \mathrm{C}$ for $30 \mathrm{~s}$, and 40 cycling stages of 95 
-C for $5 \mathrm{~s}$ and $55 \circ \mathrm{C}$ and $72 \circ \mathrm{C}$ for $30 \mathrm{~s}$ each. Rac1 primer sequences were: 5-

TCAGTTACACGACCAATGCG-3 (sense) and 5-ATGCAGGACTCACAAGGGAA-3 (antisense).

\subsection{3 western blotting analysis}

Each gram of hippocampi were homogenized with $30 \mu$ l cocktail protease inhibitor (Roche Molecular Biochemicals, Germany) and 3 ml RIPA buffer (US Biological, USA). After centrifugation at 12000 rpm (4 $\circ \mathrm{C})$, the supernatant was collected and stored at -20 •C. BCA assay and spectrophotometry were used to assess the total protein concentration. The supernatant sample (50 ug of protein) was separated by $10 \%$ SDS-PAGE and transferred to PVDF membrane (Millipore Inc., Darmstadt, Germany). After blocking with 5\% skim milk for 2 hours, the membrane was incubated with primary antibody overnight: Rac1 (1:500, sc514583, Santa Cruz Biotechnology), Tiam1 (1:500, sc-393315, Santa Cruz Biotechnology), a-chimaerin (1:500, sc-365985, Santa Cruz Biotechnology), Bcr (1:500, sc-104, Santa Cruz Biotechnology), GluR-1 (1:500, sc-13152, Santa Cruz Biotechnology), Synapsin 1(1:500, ab254349, Abcam), and PSD-95 (1:500, sc-32290, Santa Cruz Biotechnology). The specificity of these primary antibodies has been verified (Mao et al. 2017; Liu et al. 2018; Elzinga et al. 2013; Gu et al. 2018; Groh et al. 2014; Tsai et al. 2012). The membrane was incubated with a mixture of anti-rabbit IgG (Golden Bridge, Zhongshan, China) and horseradish peroxidase (HRP) for 1 hour at room temperature. Quantity One software (Bio-Rad, USA) was used for quantitative analysis.

\subsubsection{Rac1-GTP binding assay}

PAK1-PBD colored agarose beads (Rac1 Activation Assay Kit, 17-283MSDS, Sigma-Aldrich) was used to measure Rac1 activation. Briefly, $20 \mathrm{ml}$ of PAK1-PBD agarose beads were mixed with $200 \mathrm{mg}$ of sample and incubated at $4^{\circ} \mathrm{C}$ for 60 minutes, then $\mathrm{MgCl}_{2}$ was added to terminate the reaction. The treated samples were centrifuged at $12000 \mathrm{rpm}$ at $4^{\circ} \mathrm{C}$ for 15 minute, and the supernatants was removed. The precipitated complex was then cleaned 3 times with magnesium-containing lysis buffer, and boiled in the sample buffer.. After the proteins were separated by $10 \%$ SDS-PAGE, western blot analysis was performed with anti-Rac1 antibody (1:500, sc-514583, Santa Cruz Biotechnology).

\subsection{Golgi staining}

Take 6 rats from each group for Golgi staining. According to the manufacturer's instructions, solutions $A$, B, C, D and E were prepared 24 hours in advance, and using the PK 401/401A FD Rapid GolgiStain Kit (FD Neuro Technologies, USA) to prepare the brain. Use a Leica freezing microtome to obtain $100 \mu \mathrm{m}$ thick coronal sections at a temperature $\left(-20^{\circ} \mathrm{C}\right.$ to $\left.-22^{\circ} \mathrm{C}\right)$. The slices were placed in a $6 \%$ sucrose solution (prepared with 0.1MDPBS) and stored at room temperature and protected from light for 72 hours. Install each slice and dry overnight at room temperature. Immerse the section in the staining mixture (solutions D: solutions $E$ : deionized water = 1:1:2) for 10 minutes, and 50\%, 75\%, 95\% and 100\% alcohol gradient dehydration, clarified in xylene. An appropriate amount of neutral gum was dropped and cover-slip sealed. Neurons with typical hippocampal CA1 structure were selected and the density of dendritic spines were analyzed by Image $\mathrm{J}$ software. Each rat randomly selects 3 slices for analysis. For each neuron, five segments of $20 \mathrm{~mm}$ of apical dendrites with clear traces and good isolation from neighboring dendrites 
were randomly selected and imaged with a $100 \times$ oil immersion lens. The number of spines on $10 \mathrm{~mm}$ dendritic length was calculated as dendritic spines density.

\subsection{Electrophysiological study}

The field excitatory postsynaptic potentials (fEPSP) from the CA1 area of the hippocampus were recorded, and the method was performed as previously described (Ren et al. 2016). Briefly, Six rats in each group were sacrificed under $2 \%$ sodium pentobarbital anesthesia after the completion of the behavioral test. The brain was taken out and immersed in artificial cerebrospinal fluid (ACSF) at $0-4^{\circ} \mathrm{C}$ (containing: $95 \% \mathrm{O}_{2} / 5 \% \mathrm{CO}_{2}$ ). Hippocampal slices were cut into $400 \mu \mathrm{m}$ thickness using a vibratome (NVSLM-1, WPI, USA) and stored for 2 hours in a chamber oxygen-containing recording solution (in $\mathrm{mM}$ : $1.25 \mathrm{NaH}_{2} \mathrm{PO}_{4}, 26 \mathrm{NaHCO}_{3}, 124 \mathrm{NaCl}, 3 \mathrm{KCl}, 1 \mathrm{CaCl}_{2}, 1 \mathrm{MgSO}_{4}, 2$ sodium pyruvate, 10 glucose, 0.4 vitamin $\mathrm{C}, 2$ sodium lactates). The slices were placed in a recording chamber with oxygen-containing recording solution. The bipolar stimulation electrode was inserted into the radiatum layer of CA3 area to activate the Schaffer collaterals, and the glass micropipette (containing recording fluid, resistance 2-3 M $\Omega$ ) was inserted into the radiatum layer of CA1 area, then electrical stimulation was triggered and fEPSP was recorded. When the stimulus was sufficient to elicit a response and the slope was approximately $50 \%$ of the maximum response, the stimulus intensity was established. After the baseline fEPSP was stable for 0.5 hour, the high-frequency stimulation ( $100 \mathrm{~Hz}$ with 100 pulses ) was replaced to induce LTP, and recorded continuously for 1 hour. The data were analyzed by Axon Instruments system (Molecular Devices, Sunnyvale, CA, USA).

\subsection{Statistical analysis}

SPSS software (version 17.0; SPSS Inc, Chicago, III) was used for the statistical analyses. All data were expressed as mean \pm SD. The Kolmogorov-Smirnov test was used to test the normality of the variables, and the Levene test was used to test the homogeneity of variance. If the variance was homogeneous $(P>$ 0.05 ) and statistical significance was determined by one-way analysis of variance (ANOVA), followed by Bonferroni correction (post hoc tests) to multiple comparisons between the groups. Non-normal distribution or variance heterogeneity data were presented as the median and interquartile range, and the kruskal-wallis test was applied. $P<0.05$ was considered statistically significant.

\section{Results}

\subsection{S-Ketamine increased the sucrose preference percentage (SPP) in stressed rats}

SPP can accurately assess the degree of anhedonia in rats (Luo et al. 2010), and we used it to validate the CUMS model and the antidepressant effect of s-ketamine. After completion of the CUMS procedure, the data of SPP meet normality (The $P$ values of groups C, D, DK, DNK, and DN were $0.173,0.275,0.757$, $0.275,0.279)$ and homogeneity of variance $\left(F_{(4,55)}=0.855, P=0.497\right)$. As shown in Fig. 1(A), significant intergroup differences were observed among five groups $\left(F_{(4,55)}=41.530, P<0.001\right)$. The post hoc tests 
showed that the SPP in the CUMS-treated groups (group D, DK, DNK, and DN) was significantly lower than that of the group $C(P<0.001$, respectively), but no statistical difference was observed between the four CUMS-treated groups ( $P=1.000$, respectively). After s-ketamine and NSC23766 treatment, the data of SPP meet normality (The $P$ values of groups C, D, DK, DNK, and DN were $0.157,0.894,0.698,0.416$, $0.667)$ and homogeneity of variance $\left(F_{(4,55)}=0.118, P=0.976\right)$. The intergroup statistical difference was observed among these five groups $\left(F_{(4,55)}=74.030, P<0.001\right)$. Post hoc tests showed that group DK exhibited increased levels in the SPP and significantly higher than that in the D group $(P<0.001)$. Compared to group DK, group DNK showed decreased levels in the SPP $(P<0.001)$. Figure 1 (D).

\subsection{S-Ketamine alleviated the open-field behavioral performance of stressed rats}

Feeding frequency (RF) and number of crossed squares (NOCS) reflect the exploratory activities of rodents, and also used to evaluate the depression-like behavior in rats (Hallam et al. 2004). After completion of the CUMS procedure, the data of rearing frequency (RF) and number of crossed squares (NOCS) all meet normality (RF: the $P$ values of groups C, D, DK, DNK, and DN were $0.522,0.385,0.376$, $0.682,0.304$; NOCS: the $P$ values of groups C, D, DK, DNK, and DN were $0.100,0.251,0.882,0.292,0.316$ ) and homogeneity of variance (RF: $F_{(4,55)}=2.116, P=0.091$; NOCS: $\left.F_{(4,55)}=1.530, P=0.206\right)$. As shown in Fig. 1(B-C), significant intergroup differences were observed among five groups in terms of $\operatorname{RF}\left(\mathrm{F}_{(4,55)}=\right.$ 53.187, $P<0.001)$ and NOCS $\left(F_{(4,55)}=91.982, P<0.001\right)$. The post hoc tests showed that the RF and NOCS in the CUMS-treated groups (group D, DK, DNK, and DN) was significantly lower than that of the group C ( $P<0.001$, respectively), but no statistical difference was observed for RF and NOCS between the four CUMS-treated groups ( $P=1.000$, respectively). After s-ketamine and NSC23766 treatment, the data of RF and NOCS meet normality (RF: the $P$ values of groups C, D, DK, DNK, and DN were $0.075,0.488$, $0.523,0.567,0.431$; NOCS: the $P$ values of groups $C, D, D K, D N K$, and DN were $0.678,0.243,0.349,0.459$, $0.130)$ and homogeneity of variance $\left(\mathrm{RF}: \mathrm{F}_{(4,55)}=2.502, P=0.053\right.$; NOCS: $\left.\mathrm{F}_{(4,55)}=1.439, P=0.233\right)$. Significant intergroup differences were observed among five groups in terms of $\operatorname{RF}\left(F_{(4,55)}=52.039, P<\right.$ $0.001)$ and NOCS $\left(F_{(4,55)}=92.967, P<0.001\right)$. The post hoc tests showed that group DK exhibited increased levels in RF and NOCS, and significantly higher than that in the D group $(P<0.001$, respectively). Compared to group DK, group DNK showed decreased levels in RF and NOCS (both $P<$ 0.001). Figure 1(E-F).

\subsection{S-Ketamine up-regulated the level of Rac1's mRNA and protein expression in the hippocampus of stressed rats}

To determine whether Rac1 plays an important role in the antidepressant effects of s-ketamine, we analyzed the level of Rac1's mRNA and protein expression in the hippocampus of stressed rats. The data of Rac1's mRNA and protein expression all meet normality (mRNA: the $P$ values of groups C, D, DK, DNK, and DN were $0.588,0.703,0.812,0.639,0.687$; protein expression: the $P$ values of groups $C, D, D K, D N K$, 
and DN were $0.851,0.692,0.865,0.360,0.338)$ and homogeneity of variance (mRNA: $F_{(4,25)}=1.496, P=$ 0.233; protein expression: $\left.\mathrm{F}_{(4,25)}=0.653, P=0.630\right)$. As shown in Fig. $2(A-C)$, the mRNA and protein level of Rac1 among all groups showed statistically significant differences $\left(F_{(4,25)}=52.234, P<0.001\right.$ and $F_{(4 \text {, }}$ $25)=63.423, P<0.001)$. Post hoc tests showed that CUMS induced expression decrease of Rac1 in hippocampal, and the mRNA, protein level of Rac1 in the group $D$ were significantly lower than that of the group C (both $P<0.001$ ). S-Ketamine up-regulated the expression level of Rac1, and the mRNA, protein expression of Rac1 in group DK exhibited higher readings than group D (both $P<0.001$ ). However, NSC23766 failed to reverse the s-ketamine induced expression up-regulation of Rac1, and no statistical difference was observed for the mRNA and protein expression of Rac1 between the group DK and group $\operatorname{DNK}(P=1.000$ and $P=0.982)$.

\subsection{S-Ketamine increased the activity of Rac1 in the hippocampus of stressed rats}

Since the activated state GTP-Rac1 can reflect the function of Rac1, we further implemented the Rac1GTP binding assay. The data of Rac1-GTP and Rac1-GTP/Total Rac1 ratio all meet normality (Rac1-GTP: the $P$ values of groups C, D, DK, DNK, and DN were $0.762,0.982,0.760,0.332,0.369$; Rac1-GTP/Total Rac1: the $P$ values of groups C, D, DK, DNK, and DN were $0.753,0.106,0.797,0.572,0.463$ ) and homogeneity of variance $\left(\mathrm{F}_{(4,25)}=2.272, P=0.090\right.$ and $\left.\mathrm{F}_{(4,25)}=0.881, P=0.489\right)$. As shown in Fig. 2(D-E), the Rac1-GTP and Rac1-GTP/Total Rac1 ratio among all groups showed statistically significant differences $\left(\mathrm{F}_{(4,25)}=340.523, P<0.001\right.$ and $\left.\mathrm{F}_{(4,25)}=1083.035, P<0.001\right)$. Post hoc tests showed that the levels of Rac1-GTP and Rac1-GTP/Total Rac1 ratio in group D were significantly lower than that of group $C$ (both $P<0.001)$. S-Ketamine increased the activity of Rac1 in the hippocampus of stressed rats. Compared with group D, the levels of Rac1-GTP and Rac1-GTP/Total Rac1 ratio in group DK exhibited higher readings (both $P<0.001$ ). However, NSC23766 reversed the s-ketamine induced up-regulation of Rac1 activity, and the Rac1-GTP and the Rac1-GTP/Total Rac1 ratio showed a very low value in group DNK, which was significantly lower than those in the DK group (both $P<0.001$ ).

\subsection{S-Ketamine increased Tiam1 expression, and decreased a1-Chimaerin, Bcr expression in the hippocampus of stressed rats}

To study the functional status of Rac1, we further detected the expression of potential upstream activity regulatory proteins Tiam1, a1-Chimaerin and Bcr. The data of these activity-regulating proteins all meet normality (Tiam1: the $P$ values of groups C, D, DK, DNK, and DN were $0.457,0.709,0.439,0.380,0.689$; a1-Chimaerin: the $P$ values of groups C, D, DK, DNK, and DN were $0.653,0.624,0.617,0.189,0.427$; Bcr: the $P$ values of groups $\mathrm{C}, \mathrm{D}, \mathrm{DK}, \mathrm{DNK}$, and $\mathrm{DN}$ were $0.344,0.501,0.241,0.919,0.962$ ) and homogeneity of variance (Tiam1: $\mathrm{F}_{(4,25)}=0.472, P=0.756$; a1-Chimaerin: $\mathrm{F}_{(4,25)}=1.174, P=0.346$; $\mathrm{Bcr}: \mathrm{F}_{(4,25)}=1.573, P=$ 0.212). As shown in Fig. 3(A-D), the expression levels of Tiam1, a1-Chimaerin and Bcr among all groups showed statistically significant differences $\left(\mathrm{F}_{(4,25)}=164.463, P<0.001 ; \mathrm{F}_{(4,25)}=67.307, P<0.001\right.$; and $\mathrm{F}_{(4 \text {, }}$ 
$25)=89.617, P<0.001)$. Post hoc tests showed that the Tiam1 was significantly lower $(P<0.001)$, and a1Chimaerin, Bcr were higher in group $D$ than that of group $C(P<0.001$ and $P<0.001)$. Compared with group $\mathrm{D}$, the protein levels of Tiam1 exhibited increased expression $(P<0.001)$, and a1-Chimaerin, Bcr exhibited decreased expression in group DK (both $P<0.001$ ). Compared with the DK group, the protein levels of Tiam 1 and Bcr exhibited decreased expression $(P<0.001$ and $P=0.002)$, and a1-Chimaerinin exhibited increased expression in groups DNK $(P<0.001)$.

\subsection{S-Ketamine up-regulated the expression levels of synaptic protein Glur1, synapsin1 and PSD95 in the hippocampus of stressed rats}

Synaptic proteins Glur1, synapsin 1 and PSD95 were enriched in the postsynaptic membrane, and can regulate synaptic plasticity (Colledge et al. 2003; Huang et al. 2020). So we analyzed the effect of sketamine on the expression levels of these proteins. The data of synaptic proteins Glur1, synapsin1 and PSD95 all meet normality (Glur1: the $P$ values of groups C, D, DK, DNK, and DN were $0.671,0.442,0.902$, $0.108,0.317$; synapsin 1 : the $P$ values of groups C, D, DK, DNK, and DN were $0.421,0.488,0.384,0.788$, 0.264; PSD95: the $P$ values of groups C, D, DK, DNK, and DN were $0.591,0.701,0.610,0.871,0.331)$ and homogeneity of variance (Glur1: $F_{(4,25)}=1.460, P=0.244$; synapsin1: $F_{(4,25)}=0.723, P=0.584$; PSD95: $\left.\mathrm{F}_{(4,25)}=0.804, P=0.534\right)$. As shown in Fig. $4(A-D)$, the expression levels of Glur1, synapsin1 and PSD95 among all groups showed statistically significant differences $\left(F_{(4,25)}=63.077, P<0.001 ; F_{(4,25)}=63.700\right.$, $P<0.001$; and $\left.\mathrm{F}_{(4,25)}=82.779, P<0.001\right)$. Post hoc tests showed that the expression levels of Glur1, synapsin 1 and PSD95 were significantly lower in group $D$ than that of group $C$ (all $P<0.001$ ). Compared with group $D$, their expression in group DK exhibited significantly increased levels (all $P<0.001$ ). Compared with the DK group, the expression of Glur1, synapsin1 and PSD95 in groups DNK were significantly lower $(P<0.001, P<0.001$ and $P=0.002)$.

\subsection{S-Ketamine increased the spines density in the hippocampal CA1 region of stressed rats}

To determine whether the antidepressant effect of s-ketamine is related to changes in synaptic structure, we analyzed the dendritic spines density of hippocampal CA1 region in stressed rats. The data of spines density meet normality (The $P$ values of groups $C, D, D K, D N K$, and DN were $0.446,0.221,0.888,0.627$, $0.245)$ and homogeneity of variance $\left(F_{(4,25)}=0.177, P=0.948\right)$. As shown in Fig. $5(A-B)$, the spine density among all groups showed statistically significant differences $\left(F_{(4,25)}=17.544, P<0.001\right)$. Post hoc tests showed that the spine density was significantly lower in group $D$ than that of group $C(P<$ $0.001)$. Compared with group $D$, group DK exhibited increased levels of spines density $(P=0.010)$. Compared with the DK group, the spines density in groups DNK were lower $(P=0.004)$.

\subsection{S-Ketamine alleviated the LTP impairments of Schaffer- CA1 in the hippocampus of stressed rats}


Since LTP can intuitively reflect the process of synaptic plasticity, we implemented electrophysiological experiments through brain slices to study the internal mechanism of s-ketamine on the antidepressant effects in stressed rats. The data of fEPS slope meet normality (The $P$ values of groups $\mathrm{C}, \mathrm{D}, \mathrm{DK}, \mathrm{DNK}$, and $D N$ were $0.971,0.693,0.890,0.693,0.857)$ and homogeneity of variance $(P=0.985)$. As shown in Fig. $5(A-B)$, the fEPS slope among all groups showed statistically significant differences $\left(F_{(4,25)}=45.444, P<\right.$ 0.001). Post hoc tests showed that CUMS induced LTP impairment in group $D$ as compared to group $C$ (fEPS slope: $145.9 \pm 5.2 \%$ vs. $177.7 \pm 6.6 \%)(P<0.001)$. S-Ketamine effectively alleviated the LTP impairment caused by CUMS, as shown by the fEPS slope being higher in the DK group $(164.47 \pm 5.6 \%)$ than in the D group $(P<0.001)$. However, Rac1 inhibitor NSC23766 effectively reversed the protective effect of ketamine. Compared with the DK group, the fEPS slope in groups DNK $(148.9 \pm 5.2 \%)$ was lower $(P=0.001)$. Figure $6(\mathrm{~A}, \mathrm{~B})$.

\section{Discussion}

Our results showed that CUMS down-regulated the expression and activity of Rac1, decreased the dendritic spine density and the expressions of synaptic-related proteins such as Glur1, Synapsin1, and PSD95, impaired the LTP in the hippocampus, and induced depression-like behavior in rats. Ketamine can up-regulate the expression and activity of Rac1 in the hippocampus of stressed rats, increase the dendritic spine density and the expression of Glur1, Synapsin1, and PSD95, effectively reduce the CUMSinduced LTP impairments, and thus improve the depression-like behavior of rats. However, Rac1-specific inhibitor NSC23766 effectively reversed these ketamine-mediated changes in the hippocampus of rats and counteracted its antidepressant effects.

The animal model by CUMS has been proved to be very similar to humans in simulating the pathogenesis of depression, so it has good apparent, predictive, and structural validity (Nestler and Hyman 2010). The core symptom of depression is anhedonia, which can be assessed by the sucrose preference and open field test in rats. Thus it can make an accurate assessment of the degree of depression in them (Zhu et al. 2015). In this study, compared with the control group, the SPP, horizontal ambulation distance, and rearing frequency of rats in the CUMS treatment group were significantly lower, indicating that the establishment of the rat depression model in this study was successful.

Synaptic plasticity is a phenomenon wherein the transmission function of the synapse is enhanced or weakened with neural activity (Lynch 2004 ). Changes in dendritic morphology or dendritic spine density affect the transmission function of synapses (Stein et al. 2021;Muellerleile et al. 2020). Numerous studies have shown that the pathogenesis of depression is related to changes in synaptic plasticity (Yoshino et al. 2021; Lorenzetti et al. 2020). The classic SSRIs fluoxetine and vortioxetine, can not only induce synaptogenesis and enhance synaptic transmission function, but also have a good antidepressant effect (Bath et al. 2012; Waller et al. 2017). Several studies have shown that ketamine can increase synaptogenesis, up-regulate the expression of synaptic proteins, such as a-amino-3-hydroxy-5methyl-4-isoxazole-propionic acid (AMPA) receptor and PSD95 in the hippocampus of animals, and induce LTP- like changes (Li et al. 2011; Li et al. 2019; Aleksandrova et al. 2020). Our results also found 
that CUMS can not only induce depression-like behavior in rats but also cause dendritic spine loss and LTP impairments in the hippocampal CA1 region. Ketamine treatment can increase dendritic spine density and reduce LTP impairments in the hippocampus, effectively improving the depression-like behavior of stressed rats. However, pre-administration of Rac1 inhibitor reversed the ketamine-mediated synaptic plasticity changes in the hippocampus and effectively counterbalanced its antidepressant effect on stressed rats. Our results further confirm that changes in synaptic plasticity are associated with the pathogenesis of depression, and Rac1 plays a key role in the antidepressant effect of ketamine.

There are two states of intracellular Rac1, namely the activated state GTP-Rac1 and the inactivated state GDP-Rac1. Under the action of GDP/GTP exchanging factor (GEF), Rac1 changes from an inactive to an active state. Conversely, under the action of GTPase activating protein (GAP), Rac1 changes its state from an activated to inactivated state (Tolias et al. 2011). It has been found that Tiam1, Kalirin7 as GEF and a1-chimaerin, and Bcr as GAP, can specifically act on Rac1 and regulate its activity and functions (Tolias et al. 2011; Oh et al. 2010). In this study, it was found that ketamine could up-regulate the expression and activity of Rac1 in stressed rats, while pre-treatment with Rac1 inhibitor reduced the activity of Rac1, and the antidepressant effect of ketamine was significantly reversed. In addition, we also found that ketamine can increase the expression of Tiam 1 and decrease the expression of a1-chimaerin and $\mathrm{BCr}$, suggesting that the effect of ketamine on Rac1 may be mediated by regulating the upstream GEF/GAP.

As we all know, Rac1, PSD95, synapsin1 and AMPA receptors are enriched in the postsynaptic membrane. These synaptic proteins interact and regulate synaptic plasticity (Colledge et al. 2003; Huang et al. 2020). Previous studies have shown that the antidepressant effect of ketamine may be related to the upregulation of brain-derived neurotrophic factor (BDNF) and enhancement of AMPA receptor function (Li et al. 2019; Li et al. 2010). Activating Rac1 can up-regulate the expression of tropomyosin-related kinase B (TrkB), the receptor of BDNF in the hippocampus, and induce more AMPA receptors to aggregate at the synapse and enhance the excitatory postsynaptic potential (Pandya et al. 2017; Martinez and TejadaSimon 2011; Benoist et al. 2013). In this study, we found that ketamine (a non-competitive antagonist of NMDA receptor) can up-regulate the expression of PSD95, synapsin 1 and AMPA receptors subunit 1 (Glur1) in the hippocampus of stressed rats, while Rac1 inhibitor can reverse the up-regulation effect of ketamine on these proteins. Our results suggest that these synaptic-related proteins are involved in the regulation of ketamine on the synaptic plasticity in the hippocampus of stressed rats, and Rac1 plays a key role in this regulation.

Ketamine itself has certain mental side effects, and no mental behavioral abnormalities were observed in rodents after intraperitoneal injection of ketamine below $25 \mathrm{mg} / \mathrm{kg}$ (Hunt et al. 2006). Our previous study also found that $20 \mathrm{mg} / \mathrm{kg}$ of ketamine had a good antidepressant effect, but it declined with the increase in the dose (Zhu et al. 2017). Therefore, we chose $20 \mathrm{mg} / \mathrm{kg}$ of ketamine as the treatment dose for this study. Previous animal experiments showed that $50 \mathrm{mg}$ NSC23766 ICV injection would be the optimal dose according to the dose-response curve, which could effectively inhibit the activation of Rac1 GTPase in the hippocampus without showing any significant behavioral side effects (Zhang et al. 2009). In this 
study, we found that $50 \mathrm{mg}$ of NSC23766 not only significantly down-regulated the activity of Rac1 in the hippocampus of rats, but also effectively reversed the antidepressant effect of ketamine.

The mechanism of the rapid antidepressant effect of ketamine is still unclear. Our results extend the existing work and knowledge on depression by examining whether Rac1 plays an important role in the antidepressant effect of ketamine. However, the pathogenesis of depression is complex and involves multiple brain areas such as the hippocampus, prefrontal cortex, and amygdala (Qiu et al. 2021; Rezaei et al. 2021). In this study, we only observed the effect of ketamine on the hippocampus of rats. In addition, our results also found that ketamine affected the expression of many Rac1 activity regulators such as Tiam1, a1-chimaerin, and other synaptic-related proteins, but the upstream and downstream signaling pathways were not further clarified. It would be valuable to further study the effects of ketamine on other depression-related brain regions and Rac1 upstream signaling pathways.

In conclusion, s-ketamine has a good antidepressant effect. The specific mechanism of its antidepressant effect may be related to the enhancement of synaptic plasticity by up-regulating the expression and activity of Rac1 protein in the hippocampus of stressed rats, and then affecting synaptic morphology, related protein expression, and transmission function.

\section{Declarations}

\section{Conflict of interest}

The authors declare that the research was conducted in the absence of any commercial or financial relationships that could be construed as a potential conflict of interest.

\section{Author Contributions}

Fuxia Yan and Zaiping Wang designed experiments. Fuxia Yan and Zaiping Wang: Designed the study and wrote the protocol. Xianlin Zhu and Fan Zhang established the animal model of depression and performed the behavioral tests, statistical analyses and wrote the first draft of the manuscript. Yufeng You, Banglin Wu and Rongyu Zhu performed the tissue preparation, RT-qPCR and western blotting analysis. Su Yuan and Dawei Liu performed the Golgi staining. Hongbai Wang performed the electrophysiological study. All authors contributed to the article and approved the submitted version.

\section{Funding}

This work was supported by the National Natural Science Foundation of China (Grant No. 81760257), the Science and Technology Department of Hubei Province (No. 2016CFB368) and Natural Science Foundation of Yongchuan District (Ycstc, 2020nb0205).

\section{Acknowledgments}


The authors thank Jie Luo and Li Ren PhD. from the Department of Anesthesiology of the First Affiliated Hospital of Chongqing Medical University for their assistance in the study.

\section{References}

1. Aleksandrova LR, Wang YT, Phillips AG (2020) Ketamine and its metabolite, (2R,6R)-HNK, restore hippocampal LTP and long-term spatial memory in the Wistar-Kyoto rat model of depression. Mol Brain 13:92. https://doi.org/10.1186/s13041-020-00627-z

2. Angst J, Hengartner MP, Gamma A, von ZD, Angst $F$ (2013) Mortality of 403 patients with mood disorders 48 to 52 years after their psychiatric hospitalisation. Eur Arch Psychiatry Clin Neurosci 263: 425-434. https://doi.org/ 10.1007/s00406-012-0380-1

3. Banasr M, Valentine GW, Li XY, Gourley SL, Taylor JR, Duman RS (2007) Chronic unpredictable stress decreases cell proliferation in the cerebral cortex of the adult rat. Biol Psychiatry 62: 496-504. https://doi.org/10.1016/j.biopsych.2007.02.006

4. Bath KG, Jing DQ, Dincheva I, Neeb CC, Pattwell SS, Chao MV, Lee FS, Ninan I (2012) BDNF Val66Met impairs fluoxetine-induced enhancement of adult hippocampus plasticity. Neuropsychopharmacology 37: 1297-1304. https://doi.org/10.1038/npp.2011.318

5. Benoist M, Palenzuela R, Rozas C, Rojas P, Tortosa E, Morales B, González-Billault C, Ávila J, Esteban JA (2013) MAP1B-dependent Rac1 activation is required for AMPA receptor endocytosis during longterm depression. EMBO J 32: 2287-2299. https://doi.org/10.1038/emboj.2013.166

6. Chapman DP, Perry GS (2008). Depression as a major component of public health for older adults. Prev Chronic Dis 5: A22.

7. Chen LY, Rex CS, Babayan AH, Kramár EA, Lynch G, Gall CM, Lauterborn JC (2010) Physiological activation of synaptic Rac1>PAK (p-21 activated kinase) signaling is defective in a mouse model of fragile X syndrome. J Neurosci 30: 10977-10984. https://doi.org/10.1523/JNEUROSCI.1077-10.2010

8. Cipriani A, Zhou X, Del GC, Hetrick SE, Qin B, Whittington C, Coghill D, Zhang Y, Hazell P, Leucht S, Cuijpers P, Pu J, Cohen D, Ravindran AV, Liu Y, Michael KD, Yang L, Liu L, Xie P (2016) Comparative efficacy and tolerability of antidepressants for major depressive disorder in children and adolescents: a network meta-analysis. Lancet 388: 881-890. https://doi.org/10.1016/S0140-6736(16)30385-3

9. Colledge M, Snyder EM, Crozier RA, Soderling JA, Jin Y, Langeberg LK, Lu H, Bear MF, Scott JD (2003) Ubiquitination regulates PSD-95 degradation and AMPA receptor surface expression. Neuron 40:595607. https://doi.org/ 10.1016/s0896-6273(03)00687-1

10. Cornwell BR, Salvadore G, Furey M, Marquardt CA, Brutsche NE, Grillon C, Zarate CA Jr (2012). Synaptic potentiation is critical for rapid antidepressant response to ketamine in treatment-resistant major depression. Biol Psychiatry 72: 555-561. https://doi.org/10.1016/j.biopsych.2012.03.029.

11. Drevets WC (2000) Functional anatomical abnormalities in limbic and prefrontal cortical structures in major depression. Prog. Brain Res 126:413-431. https://doi.org/10.1016/S0079-6123(00)26027-5 
12. Duman RS, Aghajanian GK (2012) Synaptic dysfunction in depression: potential therapeutic targets. Science 338: 68-72. https://doi.org/10.1126/science.1222939

13. Elzinga BM, Nyhan MJ, Crowley LC, O'Donovan TR, Cahill MR, McKenna SL (2013) Induction of autophagy by Imatinib sequesters Bcr-Abl in autophagosomes and down-regulates Bcr-Abl protein. Am J Hematol 88:455-62. https://doi: 10.1002/ajh.23428

14. Golden SA, Christoffel DJ, Heshmati M, Hodes GE, Magida J, Davis K, Cahill ME, Dias C, Ribeiro E, Ables JL, Kennedy PJ, Robison AJ, Gonzalez-Maeso J, Neve RL, Turecki G, Ghose S, Tamminga CA, Russo SJ (2013) Epigenetic regulation of RAC1 induces synaptic remodeling in stress disorders and depression. Nat Med 19: 337-344. https://doi.org/10.1038/nm.3090

15. Groh C, Kelber C, Grübel K, Rössler W (2014) Density of mushroom body synaptic complexes limits intraspecies brain miniaturization in highly polymorphic leaf-cutting ant workers. Proc Biol Sci 281:20140432. https://doi: 10.1098/rspb.2014.0432

16. Gu J, Tian X, Wang W, Yang Q, Lin P, Ma Y, Xiong Y, Xu D, Zhang Y, Yang Y, Lu S, Lin Z, Luo J, Xiao F, Wang X (2018) Inhibition of Cgkii Suppresses Seizure Activity and Hippocampal Excitation by Regulating the Postsynaptic Delivery of Glua1. Cell Physiol Biochem 46:160-177. https://doi: $10.1159 / 000488419$

17. Gu L, Xie J, Long J, Chen Q, Chen Q, Pan R, Yan Y, Wu G, Liang B, Tan J, Xie X, Wei B, Su L (2013) Epidemiology of major depressive disorder in mainland china: a systematic review. PLoS One 8: e65356. https://doi.org/10.1371/journal.pone.0065356

18. Hallam KT, Horgan JE, McGrath C, Norman TR (2004) An investigation of the effect of tacrine and physostigmine on spatial working memory deficits in the olfactory bulbectomised rat. Behav Brain Res 153:481-486. https://doi.org/10.1016/j.bbr.2004.01.005

19. Hao X, Zhu X, Li P, Lv F, Min S (2016) NMDA receptor antagonist enhances antidepressant efficacy and alleviates learning-memory function impairment induced by electroconvulsive shock with regulating glutamate receptors expression in hippocampus. J Affect Disord 190:819-827. https://doi: 10.1016/j.jad.2015.11.021

20. Huang J, Shen C, Ye R, Shi Y, Li W (2021) The Effect of Early Maternal Separation Combined With Adolescent Chronic Unpredictable Mild Stress on Behavior and Synaptic Plasticity in Adult Female Rats. Front Psychiatry 12:539299. https://doi.org/10.3389/fpsyt.2021.539299

21. Hunt MJ, Raynaud B, Garcia R (2006) Ketamine dose-dependently induces high-frequency oscillations in the nucleus accumbens in freely moving rats. Biol Psychiatry 60: 1206-1214. https://doi.org/10.1016/j.biopsych.2006.01.020

22. Kang HJ, Voleti B, Hajszan T, Rajkowska G, Stockmeier CA, Licznerski P, Lepack A, Majik MS, Jeong LS, Banasr M, Son H, Duman RS (2012) Decreased expression of synapse-related genes and loss of synapses in major depressive disorder. Nat Med 18: 1413-1417. https://doi.org/10.1038/nm.2886

23. Kessler RC, Berlund P, Demler O, Jin R, Koretz D, Merikangas KR, Rush AJ, Walters EE, Wang PS (2003) The epidemiology of major depressive disorder: results for the National Comorbidity Survey Replication (NCS-R). JAMA 289:3095-3105. https://doi.org/10.1001/jama.289.23.3095 
24. Lenze EJ, Farber NB, Kharasch E, Schweiger J1, Yingling M1, Olney J, Newcomer JW (2016) Ninetysix hour ketamine infusion with co-administered clonidine for treatment-resistant depression: A pilot randomised controlled trial. World J Biol Psychiatry 26:1-9.

https://doi.org/10.3109/15622975.2016.1142607

25. Lynch MA (2004) Long-term potentiation and memory. Physiological reviews 84:87-136. doi: 10.1152/physrev.00014.2003

26. Li J, Chai A, Wang L, Ma Y, Wu Z, Yu H, Mei L, Lu L, Zhang C, Yue W, Xu L, Rao Y, Zhang D (2015) Synaptic P-Rex1 signaling regulates hippocampal long-term depression and autism-like social behavior. Proc Natl Acad Sci USA 112: E6964-6972. https://doi.org/10.1073/pnas.1512913112

27. Li JM, Liu LL, Su WJ, Wang B, Zhang T, Zhang Y, Jiang CL (2019) Ketamine may exert antidepressant effects via suppressing NLRP3 inflammasome to upregulate AMPA receptors. Neuropharmacology 146:149-153. https://doi.org/10.1016/j.neuropharm.2018.11.022

28. Li N, Liu RJ, Dwyer JM, Banasr M, Lee B, Son H, Li XY, Aghajanian G, Duman RS (2011) Glutamate Nmethyl-D-aspartate receptor antagonists rapidly reverse behavioral and synaptic deficits caused by chronic stress exposure. Biol Psychiatry 69: 754-761.

https://doi.org/10.1016/j.biopsych.2010.12.015

29. Li N, Lee B, Liu RJ, Banasr M, Dwyer JM, Iwata M, Li XY, Aghajanian G, Duman RS (2010) mTORdependent synapse formation underlies the rapid antidepressant effects of NMDA antagonists. Science 329: 959-964. https://doi.org/10.1126/science.1190287

30. Li Z, Van Aelst L, Cline HT (2000) Rho GTPases regulate distinct aspects of dendritic arbor growth in Xenopus central neurons in vivo. Nat Neurosci 3: 217-225. https://doi.org/10.1038/72920

31. Liu L, Wu B, Cai H, Li D, Ma Y, Zhu X, Lv Z, Fan Y, Zhang X (2018) Tiam1 promotes thyroid carcinoma metastasis by modulating EMT via Wnt/beta-catenin signaling. Exp Cell Res 362:532-540. https://doi: 10.1016/j.yexcr.2017.12.019

32. Qi RZ, Ching YP, Kung HF, Wang JH (2004) Alpha-chimaerin exists in a functional complex with the Cdk5 kinase in brain. FEBS Lett 561:177-80. https://doi: 10.1016/S0014-5793(04)00174-7.

33. Lorenzetti V, Costafreda SG, Rimmer RM, Rasenick MM, Marangell LB, Fu CHY (2020) Brain-derived neurotrophic factor association with amygdala response in major depressive disorder. J Affect Disord 267:103-106. https://doi.org/10.1016/j.jad.2020.01.159.

34. Luo L (2002) Actin cytoskeleton regulation in neuronal morphogenesis and structural plasticity. Annu Rev Cell Dev Biol 18: 601-635. https://doi.org/10.1146/annurev.cellbio.18.031802.150501

35. Luo KR, Hong CJ, Liou YJ, Hou SJ, Huang YH, Tsai SJ (2010) Differential regulation of neurotrophin S100B and BDNF in two rat models of depression. Prog Neuropsychopharmacol Biol Psychiatry 34:1433-1439. https://doi.org/10.1016/j.pnpbp.2010.07.033

36. Mao X, Fan C, Yu X, Chen B, Jin F (2017) DDEFL1 correlated with Rho GTPases activity in breast cancer. Oncotarget 8:112487-112497. https://doi: 10.18632/oncotarget.22095

37. Martinez LA, Tejada-Simon MV (2011) Pharmacological inactivation of the small GTPase Rac1 impairs long-term plasticity in the mouse hippocampus. Neuropharmacology 61: 305-312. 
https://doi.org/10.1016/j.neuropharm.2011.04.017

38. Muellerleile J, Blistein A, Rohlmann A, Scheiwe F, Missler M, Schwarzacher SW, Jedlicka P (2020) Enhanced LTP of population spikes in the dentate gyrus of mice haploinsufficient for neurobeachin. Sci Rep 10:16058. https://doi.org/10.1038/s41598-020-72925-4

39. Nestler EJ, Hyman SE (2010) Animal models of neuropsychiatric disorders. Nature neuroscience 13:1161-1169. https://doi.org/10.1038/nn.2647

40. Oh D, Han S, Seo J, Lee JR, Choi J, Groffen J, Kim K, Cho YS, Choi HS, Shin H, Woo J, Won H, Park SK, Kim SY, Jo J, Whitcomb DJ, Cho K, Kim H, Bae YC, Heisterkamp N, Choi SY, Kim E (2010) Regulation of synaptic Rac1 activity, long-term potentiation maintenance, and learning and memory by BCR and ABR Rac1 GTPase-activating proteins. J Neurosci 30: 14134-4144.

https://doi.org/10.1523/JNEUROSCl.1711-10.2010

41. Pandya CD, Hoda N, Crider A, Peter D, Kutiyanawalla A, Kumar S, Ahmed AO, Turecki G, Hernandez CM, Terry AV, Pillai A (2017) Transglutaminase 2 overexpression induces depressive-like behavior and impaired TrkB signaling in mice. Mol Psychiatry 22: 745-753.

https://doi.org/10.1038/mp.2016.199

42. Pennucci R, Talpo F, Astro V, Montinaro V, Morè L, Cursi M, Castoldi V, Chiaretti S, Bianchi V, Marenna S, Cambiaghi M, Tonoli D, Leocani L, Biella G, D'Adamo P, de Curtis I (2016) Loss of Either Rac1 or Rac3 GTPase Differentially Affects the Behavior of Mutant Mice and the Development of Functional GABAergic Networks. Cereb Cortex 26: 873-890. https://doi.org/10.1093/cercor/bhv274

43. Qiu A, Zhang H, Wang C, Chong YS, Shek LP, Gluckman PD, Meaney MJ, Fortier MV, Wu Y (2021) Canonical TGF-beta signaling regulates the relationship between prenatal maternal depression and amygdala development in early life. Transl Psychiatry 11:170. https://doi.org/10.1038/s41398-02101292-z

44. Rajkowska G, Miguel-Hidalgo J J, Wei J, Dilley G, Pittman S D, Meltzer H Y, Overholser J C, Roth B L, Stockmeier C A (1999) Morphometric evidence for neuronal and glial prefrontal cell pathology in major depression. Biol. Psychiatry 45:1085-1098. https://doi.org/10.1016/s0006-3223(99)00041-4

45. Ren L, Zhang F, Min S, Hao X, Qin P, Zhu X (2016) Propofol ameliorates electroconvulsive shockinduced learning and memory impairment by regulation of synaptic metaplasticity via autophosphorylation of CaMKIla at Thr 305 in stressed rats. Psychiatry Res 240:123-130. https://doi.org/10.1016/j.psychres.2016.03.053

46. Rezaei M, Shariat Bagheri MM, Ahmadi M (2021) Clinical and demographic predictors of response to anodal tDCS treatment in major depression disorder (MDD). J Psychiatr Res 138:68-74. https://doi.org/10.1016/j.jpsychires.2021.03.047

47. Sinyor M, Schaffer A, Levitt A (2010) The sequenced treatment alternatives to relieve depression $\left(S T A R{ }^{*}\right.$ ) trial: a review. Can J Psychiatry 55: 126-35. https://doi.org10.1177/070674371005500303

48. Stein IS, Park DK, Claiborne N, Zito K (2021) Non-ionotropic NMDA receptor signaling gates bidirectional structural plasticity of dendritic spines. Cell Rep 34:108664. https://doi.org/10.1016/j.celrep.2020.108664 
49. Tolias KF, Duman JG, Um K (2011) Control of synapse development and plasticity by Rho GTPase regulatory proteins. Prog Neurobiol 94: 133-148. https://doi.org/10.1016/j.pneurobio.2011.04.011

50. Tsai NP, Wilkerson JR, Guo W, Maksimova MA, DeMartino GN, Cowan CW, Huber KM.Tsai NP, Wilkerson JR, Guo W, Maksimova MA, DeMartino GN, Cowan CW, Huber KM (2012) Multiple autismlinked genes mediate synapse elimination via proteasomal degradation of a synaptic scaffold PSD95. Cell 151:1581-94. https://doi: 10.1016/j.cell.2012.11.040

51. Um K, Niu S, Duman JG, Cheng JX, Tu YK, Schwechter B, Liu F, Hiles L, Narayanan AS, Ash RT, Mulherkar S, Alpadi K, Smirnakis SM, Tolias KF (2014) Dynamic control of excitatory synapse development by a Rac1 GEF/GAP regulatory complex. Dev Cell 29: 701-715. https://doi.org/10.1016/j.devcel.2014.05.011

52. Waller JA, Tamm JA, Abdourahman A, Pehrson AL, Li Y, Cajina M, Sánchez C (2017) Chronic vortioxetine treatment in rodents modulates gene expression of neurodevelopmental and plasticity markers. Eur Neuropsychopharmacol 27:192-203. https://doi.org/10.1016/j.euroneuro.2016.11.014

53. Wang X, Chen Y, Zhou X, Liu F, Zhang T, Zhang C (2012) Effects of propofol and ketamine as combined anesthesia for electroconvulsive therapy in patients with depressive disorder. J ECT 28:128-132. https://doi.org/10.1097/YCT.0b013e31824d1d02

54. Yoshino Y, Roy B, Dwivedi Y (2021) Differential and unique patterns of synaptic miRNA expression in dorsolateral prefrontal cortex of depressed subjects. Neuropsychopharmacology 46:900-910. https://doi.org/ 10.1038/s41386-020-00861-y

55. Zhang QG, Wang R, Han D, Dong Y, Brann DW (2009) Role of Rac1 GTPase in JNK signaling and delayed neuronal cell death following global cerebral ischemia. Brain Re 1265:138-147. https://doi.org/10.1016/j.brainres.2009.01.033

56. Zhu X, Hao X, Luo J, Min S, Xie F, Zhang F (2015) Propofol inhibits inflammatory cytokine-mediated glutamate uptake dysfunction to alleviate learning/memory impairment in depressed rats undergoing electroconvulsive shock. Brain Res 1595:101-109. https://doi.org/10.1016/j.brainres.2014.07.046

57. Zhu X, Ye G, Wang Z, Luo Jie, Hao X (2017) Sub-anesthetic doses of ketamine exert antidepressantlike effects and upregulate the expression of glutamate transporters in the hippocampus of rats. Neurosci Lett 639:132-137. https://doi.org/10.1016/j.neulet.2016.12.070

\section{Figures}


A

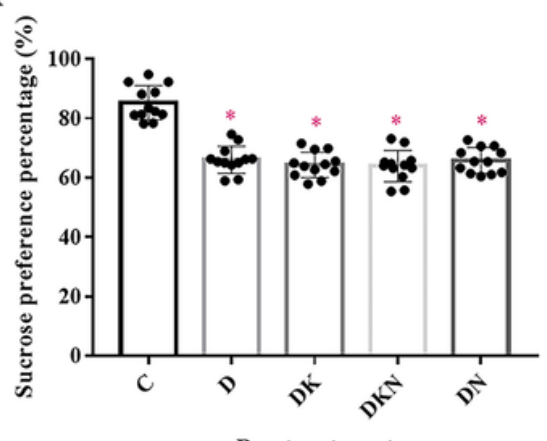

D

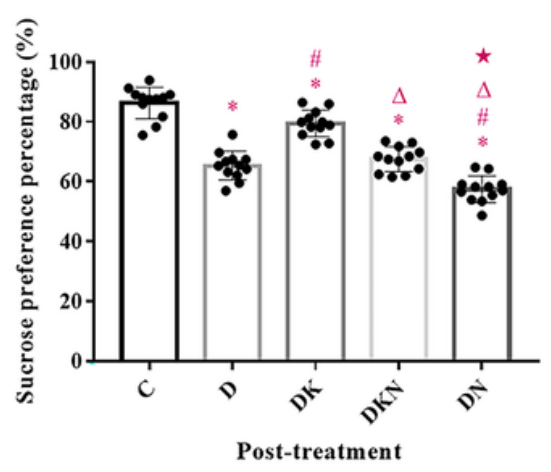

B

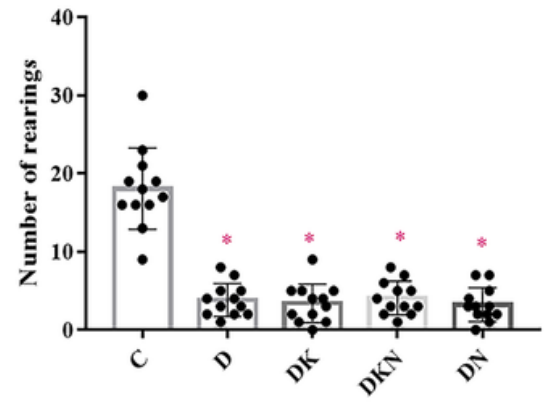

Pre-treatment

$\mathbf{E}$

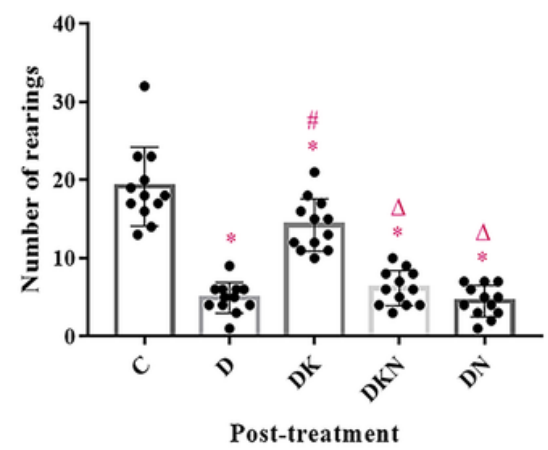

C

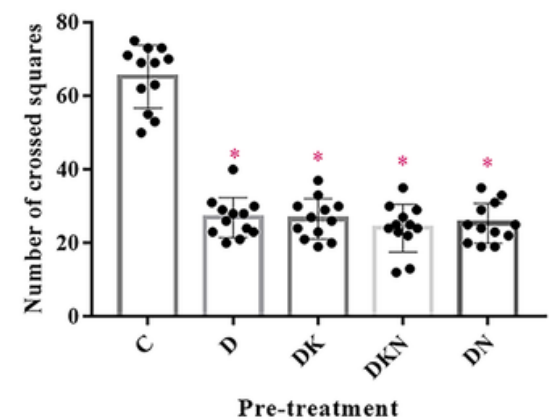

F

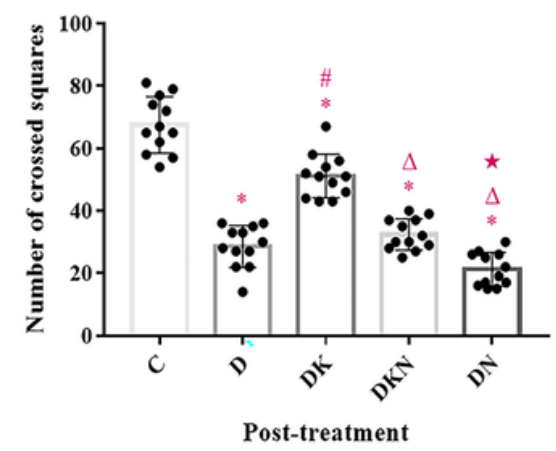

Figure 1

S-ketamine alleviated the depression-like behavior of stressed rats, which was effectively reversed by preadministration of Rac1 inhibitor NSC23766. Group C: healthy control rats; Group D: stressed rats; Group DK: stressed rats with ketamine treatment; Group DNK: stressed rats with NSC23766 and ketamine treatment; Group DN: stressed rats with NSC23766 treatment; Pre-and post-treatment: time points before and after the rats received ketamine and/or NSC23766 treatment. (A and D): the sucrose preference percentage (\%) of rats; (B and $\mathrm{E})$ : the frequency of rearing (indicating exploratory activities); ( $\mathrm{C}$ and $\mathrm{F}$ ): the number of squares crossed of rats (indicating spontaneous locomotor). Data are expressed as mean \pm

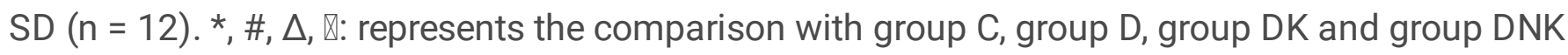
respectively, $\mathrm{P}<0.05$. 
$\mathbf{A}$

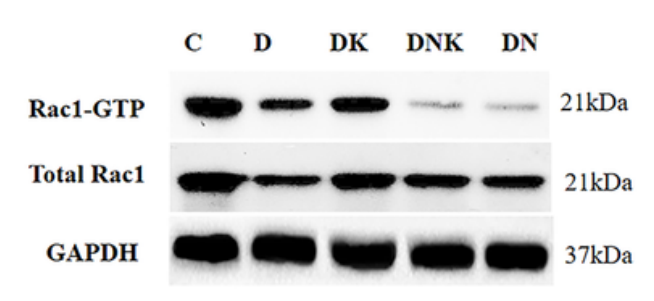

D

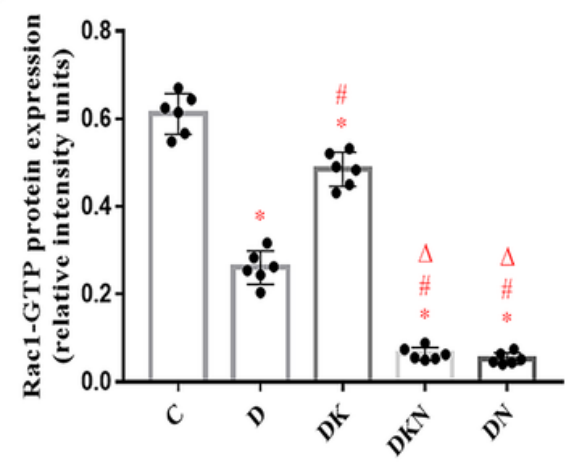

B

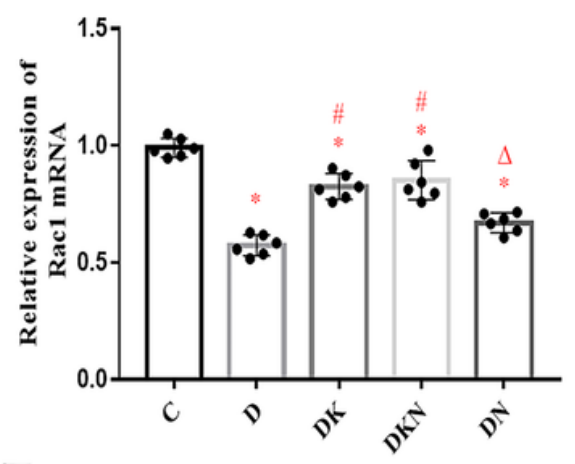

$\mathbf{E}$

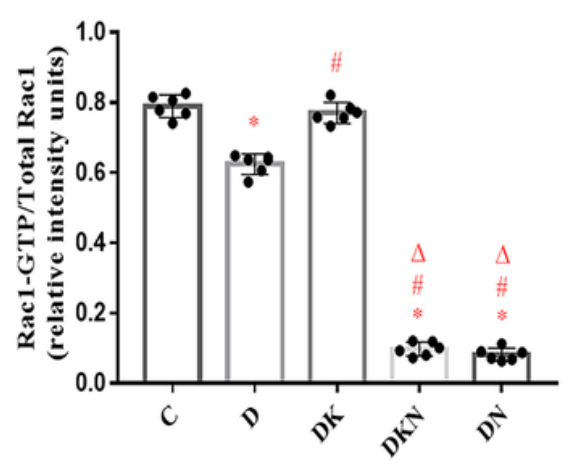

\section{C}

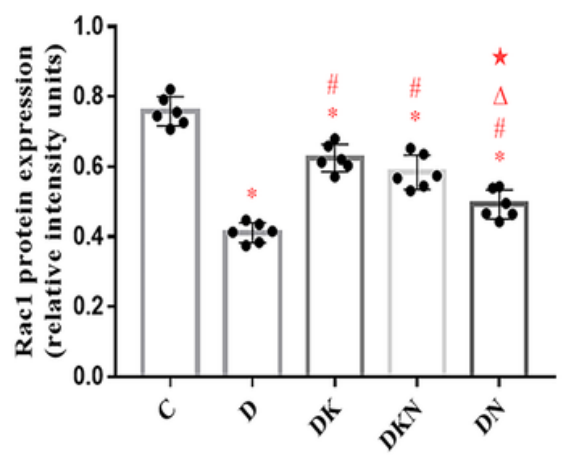

\section{Figure 2}

S-Ketamine up-regulated the expression and activity of Rac1 in the hippocampus of stressed rats, and pre-administration of Rac1 inhibitor NSC23766 effectively reversed the up-regulation of activity induced by s-ketamine. Group C: healthy control rats; Group D: stressed rats; Group DK: stressed rats with ketamine treatment; Group DNK: stressed rats with NSC23766 and ketamine treatment; Group DN: stressed rats with NSC23766 treatment. Data are expressed as mean \pm SD $(n=6)$. (A) The western blotting band of Rac1 and Rac1-GTP, proteins assessed on the same loading controls and original band see (supplementary files); (B) The mRNA level of Rac1 in the hippocampus; (C) The protein expression level of Rac1 in the hippocampus; (D, E) The results of Rac1 activity analysis. ${ }^{*}, \#, \Delta$ : represents the comparison with group $C$, group $D$ and group DK respectively, $P<0.05$. 

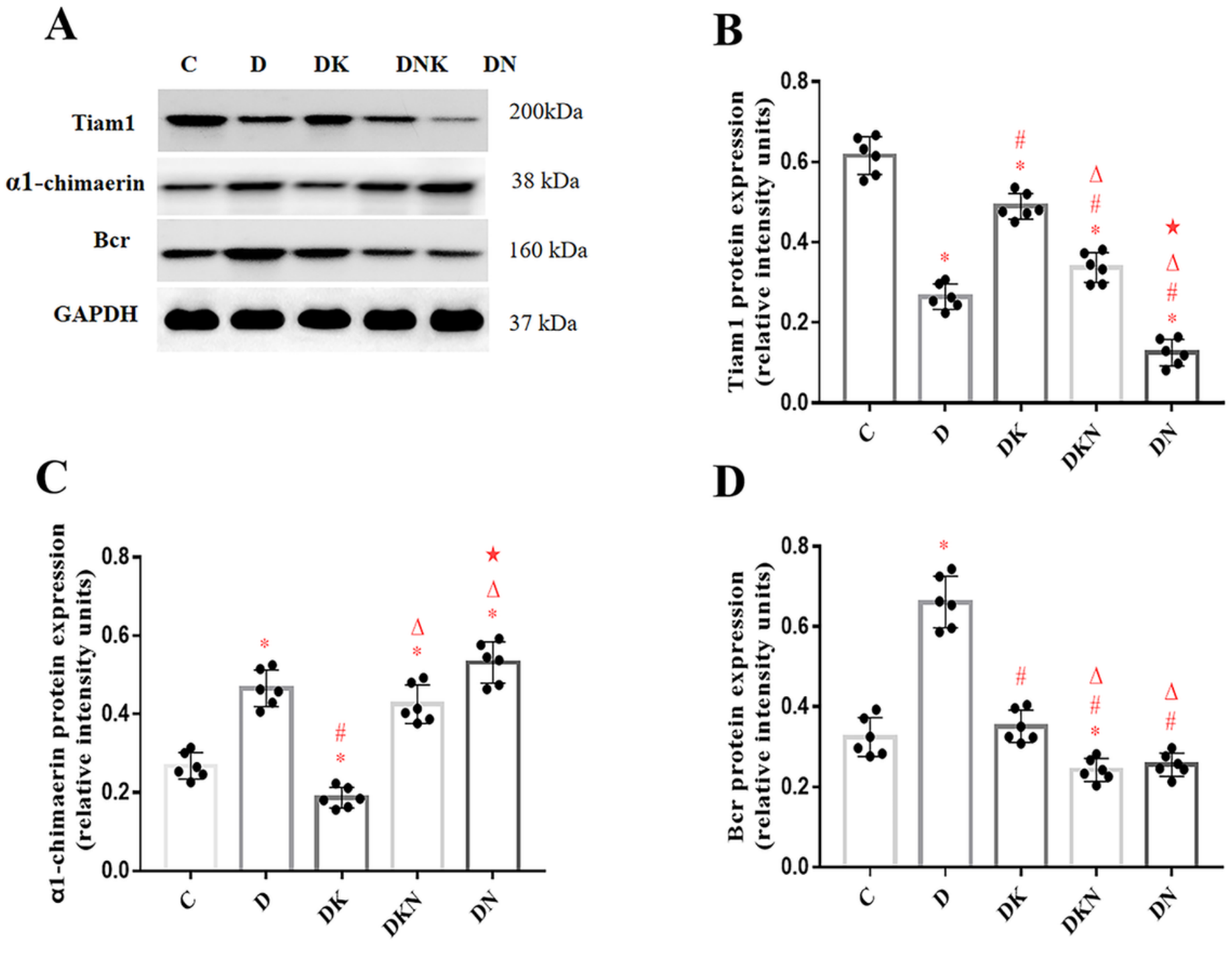

Figure 3

S-ketamine increased the expression of Tiam1 (GEF), and decreased the expression of a1-Chimaerin and Bcr (GAP) in the hippocampus of stressed rats, which was effectively reversed by pre-administration of Rac1 inhibitor NSC23766. Group C: healthy control rats; Group D: stressed rats; Group DK: stressed rats with ketamine treatment; Group DNK: stressed rats with NSC23766 and ketamine treatment; Group DN: stressed rats with NSC23766 treatment. Data are expressed as mean \pm SD $(n=6)$. (A) The western blotting band of Tiam1, a1-Chimaerin, and Bcr, proteins assessed on the same proteins assessed on the same loading controls and original band see (supplementary files); (B) The protein expression level of Tiam1 in the hippocampus; (C) The protein expression level of a1-Chimaerin in the hippocampus; (D) The protein expression level of Bcr in the hippocampus. *, \#, $\Delta$ : represents the comparison with group $C$, group D and group DK respectively, $P<0.05$. GEF: GDP/GTP exchanging factor, make Rac1 changes from an inactive to an active state; GAP: GTPase activating protein, make Rac1 changes from an active to an inactive state. 
A

\section{D DK DNK DN}

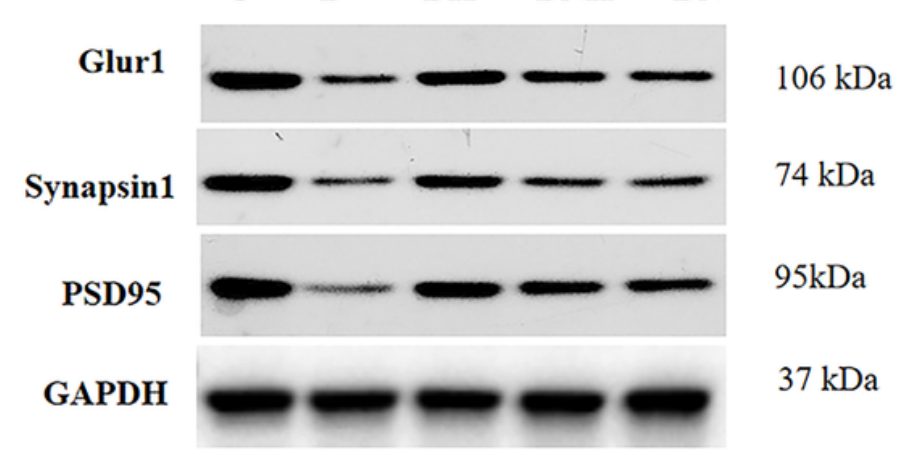

C

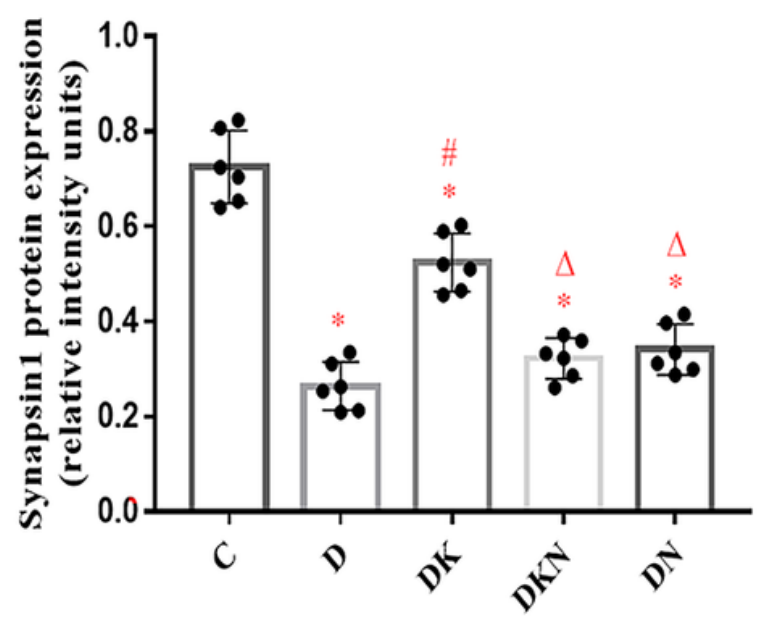

B
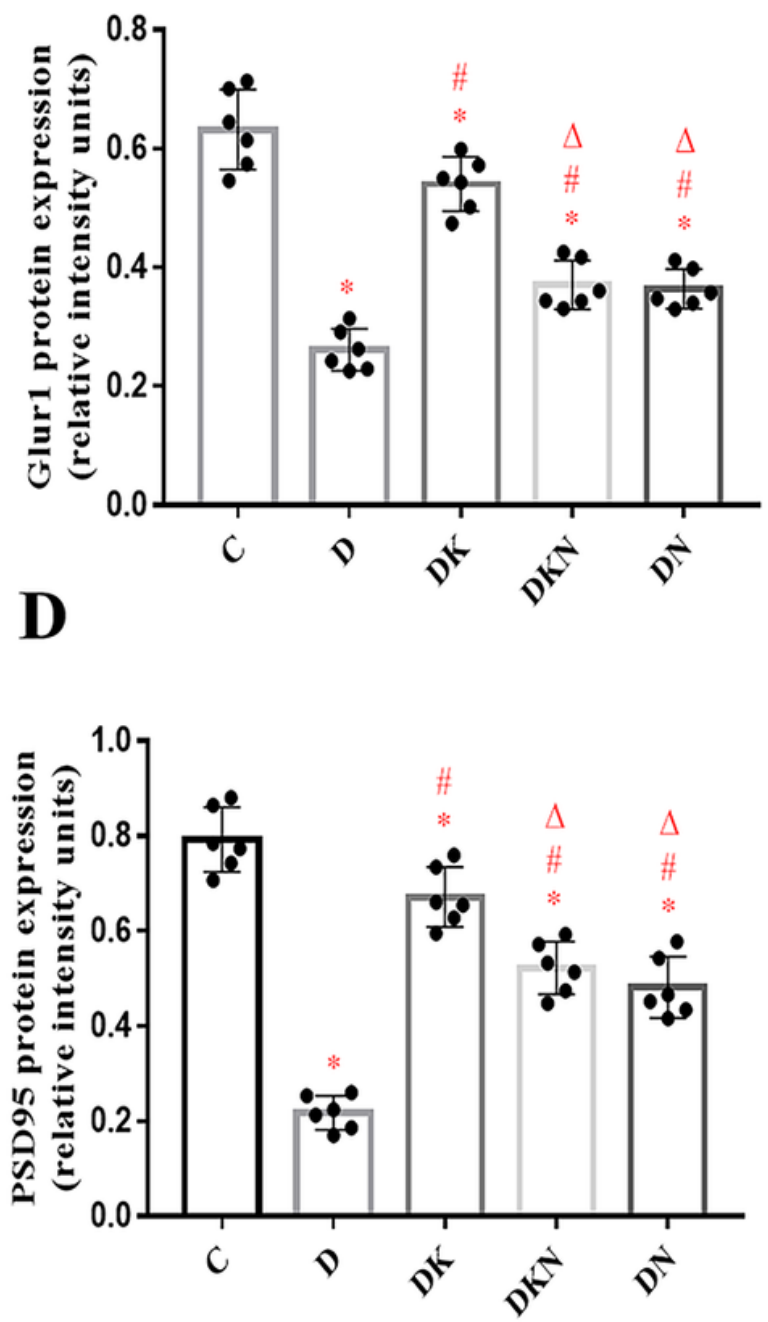

\section{Figure 4}

S-Ketamine up-regulated the expression of synaptic protein Glur1, synapsin1 and PSD95 in the hippocampus of stressed rats, which was effectively reversed by pre-administration of Rac1 inhibitor NSC23766. Group C: healthy control rats; Group D: stressed rats; Group DK: stressed rats with ketamine treatment; Group DNK: stressed rats with NSC23766 and ketamine treatment; Group DN: stressed rats with NSC23766 treatment. Data are expressed as mean \pm SD $(n=6)$. (A) The western blotting band of Glur1, synapsin 1 and PSD95, proteins assessed on the same proteins assessed on the same loading controls and original band see (supplementary files); (B) The expression level of Glur1 in the hippocampus; (C) The expression level of synapsin1 in the hippocampus; (D) The expression level of PSD 95 in the hippocampus. *, \#, $\Delta$ : represents the comparison with group $C$, group $D$ and group $D K$ respectively, $\mathrm{P}<0.05$. 
A

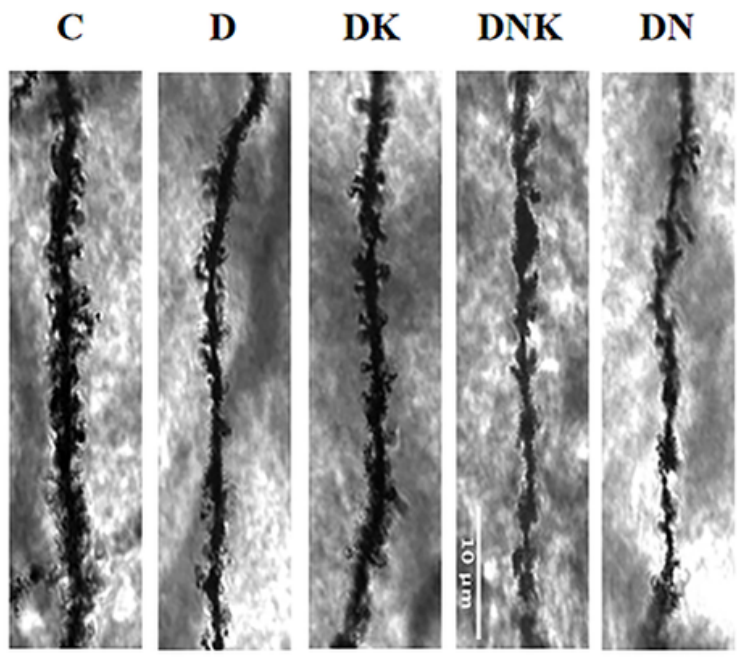

B

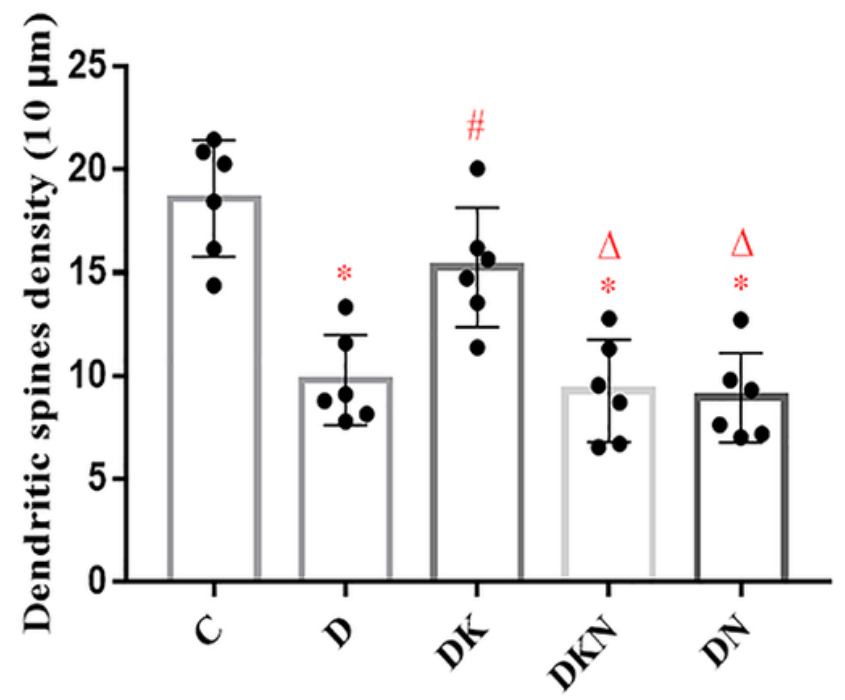

Figure 5

S-Ketamine increased the spines density in the hippocampal CA1 region of stressed rats, which was effectively reversed by pre-administration of Rac1 inhibitor NSC23766. Group C: healthy control rats; Group D: stressed rats; Group DK: stressed rats with ketamine treatment; Group DNK: stressed rats with NSC23766 and ketamine treatment; Group DN: stressed rats with NSC23766 treatment. (A) Representative image of dendrite spines in the hippocampal CA1 region. Scale bars $=10 \mu \mathrm{m}$; (B) The quantitative analysis of dendritic spines density in the hippocampal CA1 region. Data are expressed as mean $\pm S D(n=6) .{ }^{*}, \#, \Delta$ : represents the comparison with group $C$, group $D$ and group $D K$ respectively, $P$ $<0.05$. 

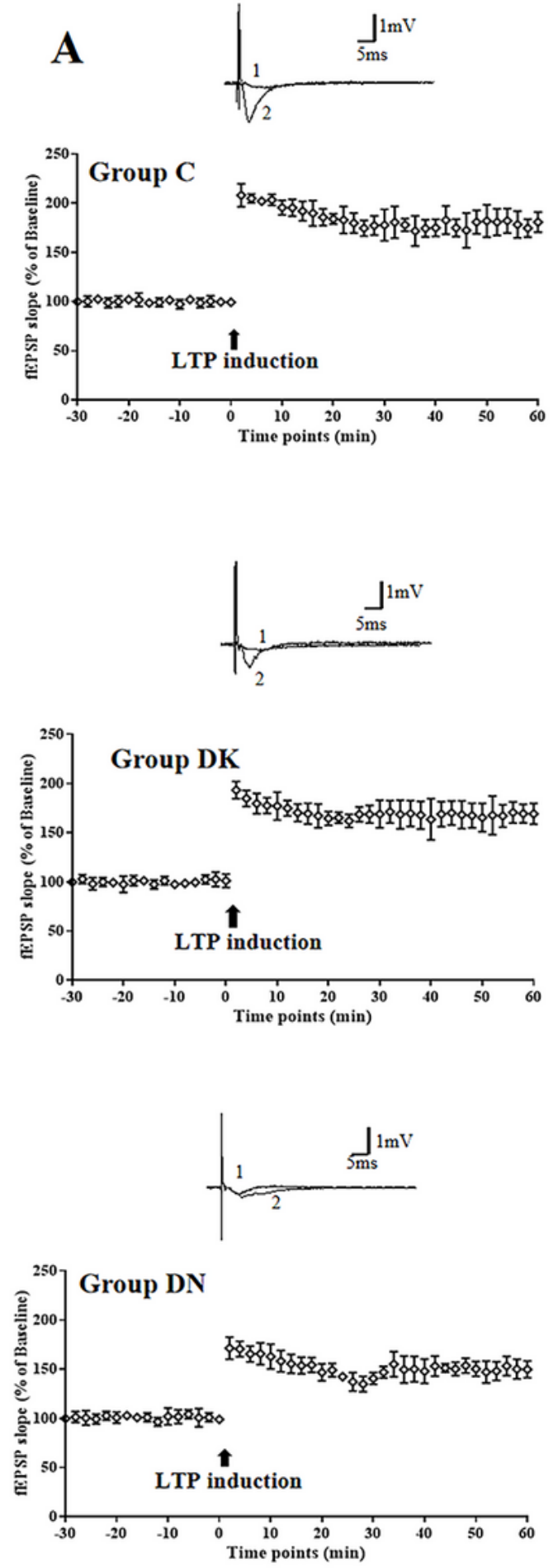
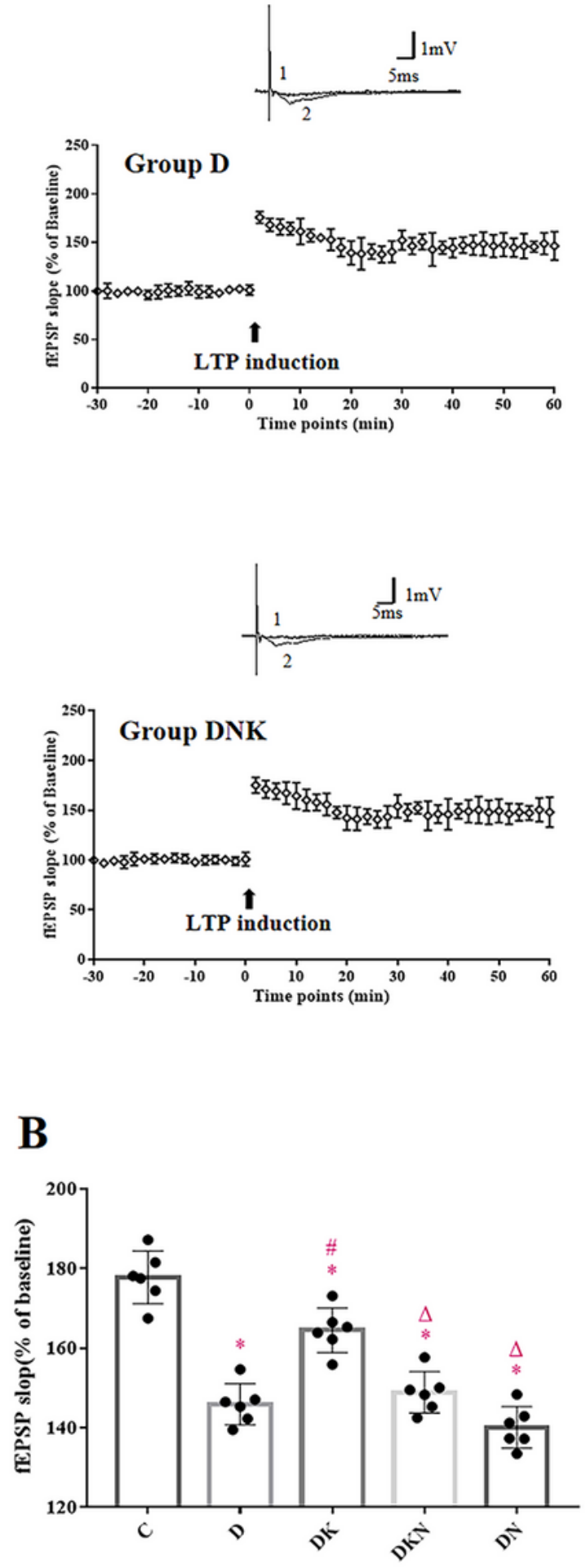

\section{Figure 6}

S-Ketamine alleviated the CUMS-induced LTP impairments of Schaffer-CA1 in the hippocampus of stressed rats, which was effectively reversed by pre-administration of Rac1 inhibitor NSC23766. Group C: healthy control rats; Group D: stressed rats; Group DK: stressed rats with ketamine treatment; Group DNK: stressed rats with NSC23766 and ketamine treatment; Group DN: stressed rats with NSC23766 treatment. (A) shows the original trace of fEPSP. Trace 1 represents the baseline, and trace 2 represents the post- 
stimulation. The scales of the horizontal and vertical lines are $5 \mathrm{~ms}$ and $1 \mathrm{mv}$, respectively. (B) shows the statistical analysis results of LTP between groups. Data are expressed as mean $\pm \operatorname{SD}(n=6) . *, \#, \Delta$ : represents the comparison with group $C$, group $D$ and group $D K$ respectively, $P<0.05$. LTP: long-term potentiation; fEPSP: field excitatory postsynaptic potential.

\section{Supplementary Files}

This is a list of supplementary files associated with this preprint. Click to download.

- Supplementaryfiles.pdf 